\title{
On the Spatial Scales to be Resolved by the Surface Water and Ocean Topography Ka-Band Radar Interferometer
}

\author{
Jinbo Wang, Lee-Lueng Fu, And Hector S. Torres \\ Jet Propulsion Laboratory, California Institute of Technology, Pasadena, California \\ SHUIMING CHEN AND Bo QIU \\ University of Hawai'i at Mānoa, Honolulu, Hawaii \\ DIMITRIS MENEMENLIS \\ Jet Propulsion Laboratory, California Institute of Technology, Pasadena, California
}

(Manuscript received 16 July 2018, in final form 19 November 2018)

\begin{abstract}
The Surface Water and Ocean Topography (SWOT) mission aims to measure the sea surface height (SSH) at a high spatial resolution using a Ka-band radar interferometer (KaRIn). The primary oceanographic objective is to characterize the ocean eddies at a spatial resolution of $15 \mathrm{~km}$ for $68 \%$ of the ocean surface. This resolution is derived from the ratio between the wavenumber spectrum of the conventional altimeter (projected to submesoscale) and the SWOT SSH errors. While the $15-\mathrm{km}$ threshold is useful as a global approximation of the spatial scales resolved by SWOT (SWOT scale), it can be misleading for regional studies. Here we revisit the problem using a high-resolution ( $\sim 2-\mathrm{km}$ horizontal grid spacing) tide-resolving global ocean simulation and map the SWOT scale as a function of location and season. The results show that the SWOT scale increases, in general, from about $15 \mathrm{~km}$ at low latitudes to $\sim 30-45 \mathrm{~km}$ at mid- and high latitudes but with a large geographical dependence. A SWOT scale smaller than $30 \mathrm{~km}$ is expected in the highlatitude energetic regions. The SWOT scale varies seasonally as a result of the seasonality in both the noise and ocean signals. The seasonality also has a geographical dependence. Both eddies and internal gravity waves/tides contribute significantly to the SWOT scale variation. Our analysis provides model predictions for interpreting the anticipated observations from SWOT and guidance for the development of analysis methodologies.
\end{abstract}

\section{Introduction}

Satellite altimetry has revolutionized physical oceanography during the past three decades by measuring the global sea surface height (SSH) with high precision and revealing not only the patterns of global sea level change (Church and White 2006), which has a direct societal impact (IPCC 2014), but also the structures of the large mesoscale $[O(100) \mathrm{km}]$ eddies (e.g., Fu et al. 2010; Chelton et al. 2011a), which are an intrinsic component of ocean circulation and climate. A knowledge of the details of the oceanic eddy field is important in quantifying the transport of heat and oceanic tracers such as carbon, oxygen, and heat, which in turn significantly influence other components of Earth's climate system (Jayne and Marotzke 2002; Chelton et al. 2011b; Gaube

\footnotetext{
Corresponding author: Jinbo Wang, jinbow@alum.mit.edu
}

et al. 2013). The conventional nadir-looking altimeters, such as TOPEX/Poseidon, the Joint Altimetry Satellite Oceanography Network (Jason) mission series, CryoSat-2, and Satellite with Argos Data Collection System (Argos) and Ka-Band Altimeter (AltiKa; SARAL), provide one dimensional (1D) SSH along their nadir tracks, resolving wavelengths down to about $50-100 \mathrm{~km}$ depending on the specific satellite and geographic locations (Dufau et al. 2016). However, because of the large gaps between 1D satellite tracks, the high along-track resolution of the altimeter data is degraded in the postprocessed two-dimensional (2D) SSH maps (e.g., in the AVISO gridded product) to longer wavelengths (150-200 km; Ducet et al. 2000). While wavenumber spectrum analyses based on alongtrack altimeters have significantly increased our understanding of the diversity of the oceanic mesoscale turbulence, the resolution of the gridded SSH products 
is not sufficient for studying the submesoscale ocean eddies, which play an important role in the vertical transport of heat and carbon in the upper ocean and in connecting the energy pathways from large-scale ocean circulation to small-scale dissipation, as has been demonstrated by several numerical studies during the past decades (e.g., Klein and Lapeyre 2009; McWilliams 2016).

As the next-generation satellite altimeter, the Surface Water and Ocean Topography (SWOT) mission will use a Ka-band radar interferometer (KaRIn) to measure the elevation of the water surface both on land and over the ocean in a wide swath (Durand et al. 2010; Fu and Ubelmann 2014, hereafter FU14). It is a NASA-CNES mission with international partnerships from Canadian and U.K. space agencies. For oceanography, its main novelty resides in its wide swaths $(50 \mathrm{~km}$ on either side of the nadir) and low instrument noise. Wide-swath altimetry is expected to reveal the detailed structures of oceanic eddies, as opposed to the coarse-resolution, interpolated 2D SSH altimetry products derived from 1D nadir altimetry (Gaultier et al. 2016). For a significant wave height of $\sim 2 \mathrm{~m}$, the KaRIn instrument noise, about $2 \mathrm{~cm}^{2}$ per cycle per kilometer $(\mathrm{cpkm})$ white noise spectral floor, is much lower than that of the conventional nadir altimeter $\left[\sim 100 \mathrm{~cm}^{2}(\mathrm{cpkm})^{-1}\right.$ noise floor]. The low instrument noise significantly increases the capability of KaRIn to resolve the small-scale SSH variability. However, the resolution capability and its global and seasonal variations remain largely unexplored because of the sparseness of observations. Nevertheless, it is important to use any information currently available to infer the SWOT resolution capability, and therefore identify the potential advantages and disadvantages of the upcoming SWOT measurements. Such an analysis will help in the planning of crucial mission activities, such as the in situ field campaign for satellite calibration and validation (CalVal) (Wang et al. 2018) as well as the SWOT data analysis strategies.

Fu and Ferrari (2008) and FU14 estimated the spatial scales that will be resolved by SWOT, the SWOT scale $L_{s}$. The FU14 estimate of $L_{s}$ was used in the mission's science requirement document. The SWOT scale is defined as the wavelength where the signal-to-noise ratio (SNR) becomes one. The noise floor was derived from the first version of the estimated SWOT measurement error budget. The true $\mathrm{SSH}$, shorter than about 70-km wavelength, is largely unknown in the conventional nadir-altimetery data because of inadequate SNR. As a result, the signal was derived from the along-track Jason-2 altimeter by extrapolating the wavenumber spectra from the large mesoscale range $(100-500 \mathrm{~km})$ under the assumption that the spectrum slope is constant in the $15-500-\mathrm{km}$ wavelength range, which is not true if internal gravity waves (IGWs) are considered. The estimated SWOT scale was $15-35 \mathrm{~km}$, with a large geographic variation resulting from variations in the wavenumber spectral slope (FU14).

FU14 provided a useful guideline for the anticipated SWOT resolution. But recent instrument and science developments require further examination for three reasons: 1) the KaRIn noise was considered as a constant globally in FU14, while it should be a function of significant wave height (SWH). A recent analysis (Dufau et al. 2016) includes the wave height dependence but still remains incomplete. 2) The energy level of the ocean signal was extrapolated from the mesoscale range in the wavenumber space assuming a constant slope (Fu and Ferrari 2008; FU14; Dufau et al. 2016), but the true spectral slope remains largely unknown. 3) The entanglement of IGWs with geostrophic eddies in the smaller submesoscale range imposes great challenges for the scientific application and interpretation of the SWOT measurements (Qiu et al. 2018), but the extent of those challenges remains unclear.

This study aims to address three open questions. 1) The climatology of the SWH as a function of geographic location and time was applied in the estimation of the KaRIn noise level. 2) A state-of-the-art high-resolution (1/48 ) global ocean simulation was used to represent a more realistic SSH signal for wavelengths shorter than $300 \mathrm{~km}$, instead of using the extrapolation of the altimeter-derived SSH spectra. 3) The energetic IGWs are considered in the total SSH signal because the global ocean simulation has a realistic tidal forcing.

The paper is organized as follows: the methodology, results, and conclusions and discussions are presented in sections $2-4$, respectively.

\section{Methodology}

\section{a. The tide-resolving global ocean simulation}

The analyses of this paper are based on a global ocean simulation recently produced by a collaborative effort between the Massachusetts Institute of Technology (MIT) and NASA's Jet Propulsion Laboratory (JPL) and the Ames Research Center (ARC). The simulation is based on the MIT general circulation model (MITgcm; Marshall et al. 1997) and has a nominal horizontal grid spacing of $1 / 48^{\circ}(\sim 2 \mathrm{~km}$ at midlatitudes) and 90 levels with $1-\mathrm{m}$ vertical grid spacing at the surface, gradually increasing to $\sim 300 \mathrm{~m}$ near the $5000-\mathrm{m}$ depth. The $\sim 2-\mathrm{km}$ grid can produce physically meaningful signals larger than roughly $10 \mathrm{~km}$, which is sufficient for our focus wavelengths of $15-150 \mathrm{~km}$. 
In the horizontal, the simulation uses a so-called latitudelongitude-polar cap (LLC) configuration (Forget et al. 2015). The global ocean is discretized into four facets with $4320 \times 12960$ grid cells and a fifth facet, the polar cap, with $4320 \times 4320$ grid cells. Hence, the simulation will be referred to as LLC4320, as it was in several recent papers (Rocha et al. 2016a,b; Wang et al. 2018; Su et al. 2018; Qiu et al. 2018). The model is forced with 6-hourly near-surface atmospheric fields (10-m winds, $2-\mathrm{m}$ air temperature and humidity, downwelling long- and shortwave radiation, precipitation, and atmospheric pressure) from the $0.14^{\circ} \mathrm{ECMWF}$ atmospheric reanalysis starting in 2011. Surface fluxes are derived using the bulk formulas of Large and Yeager (2004). Additional atmospheric pressure was added to represent forcing of major barotropic tides. This tidal forcing is crucial for generating realistic IGWs that significantly contribute to the SSH variance at the SWOT-targeted scales $(15-150 \mathrm{~km})$. The simulation starts from a coarser-resolution $\left(1 / 24^{\circ}\right)$ spinup on 10 September 2011 and is integrated for 14 months to 15 November 2012. Model prognostic variables (SSH, velocity, temperature, salinity, snow thickness and sea ice thickness, concentration, and velocity), surface fluxes (stress, heat, freshwater), bottom pressure, and planetary boundary layer depth were saved at hourly intervals. More details of the model setup can be found in previous publications (Rocha et al. 2016a,b; Wang et al. 2018; Savage et al. 2017; Qiu et al. 2018). The analyses below are based on the period between 11 November 2011 and 11 November 2012.

Existing results point to the realism of this simulation. C. Wunsch (2016, unpublished manuscript) evaluated the model internal gravity waves using the historical mooring data collected at site $\mathrm{D}\left(39^{\circ} 10^{\prime} \mathrm{N}\right.$, $\left.70^{\circ} 00^{\prime} \mathrm{W}\right)$ in the west Atlantic Ocean by the Woods Hole Oceanographic Institution (Thompson 1971; Rhines 1971) and concluded that "Consistency is found with the basic assumptions of horizontal isotropy, no imbalance in vertical energy fluxes, and power law behavior"; however, "the baroclinic M2 tide does differ substantially in the model in showing prominent tidal overtones not visible in the data." Rocha et al. (2016a) compared the model with the ADCP transects in the Drake Passage by applying the 1D Helmholtz decomposition (Bühler et al. 2014) and concluded that LLC4320 agrees with observations in both the rotational and divergent components. Wang et al. (2018) compared the mean and eddy kinetic energy (EKE) between LLC4320 and the ADCP velocity collected by the Japan Meteorological Agency during the period 2004-16 (Qiu et al. 2017) and showed that the LLC4320 reproduces the narrow subsurface zonal jets in the western Pacific from low to midlatitude with realistic jet widths and amplitudes. The mesoscale EKE in LLC4320 also agrees with the EKE in AVISO data except for the Gulf Stream extension and equatorial regions (Qiu et al. 2018). Another data-model comparison has been done by Savage et al. (2017) based on measurements of a McLane profiler at nine different locations covering the Indian, Pacific, and Atlantic Oceans. Although these comparisons point to a somewhat superior performance of the LLC4320 relative to other models at high frequencies, Savage et al. (2017) also establish that the LLC4320 contains excessive internal wave energy at tidal peaks and overtones. Despite the known (and unknown) model deficiencies of the LLC4320 simulation, it remains at present the highestresolution global ocean simulation that includes tidal forcing; therefore, it has the most realistic wavenumber spectrum in the IGW band (Arbic et al. 2018). The model results presented herein should be viewed as a preliminary, imperfect prediction, to be improved upon as better observations and numerical simulations become available.

\section{b. The simulation of the SWOT measurements}

The synthetic SWOT observations were generated by interpolating the LLC4320 SSH onto the SWOT swaths generated by the SWOT simulator (https:// github.com/SWOTsimulator; Gaultier et al. 2016) with the science orbit (21-day repeat). The synthetic data do not include instrument or correlated errors, so they are used as the true ocean signal and compared to specified error in the wavenumber space in the later analyses. The specific timing of the orbit is not important for our purpose and is discarded here to reduce the complexity of the analyses without losing proper statistics. The barotropic signals, which have scales much larger than $150 \mathrm{~km}$, are eliminated by removing the linear trend of an individual segment in the along-track direction (Wang et al. 2018).

\section{c. KaRIn noise}

The KaRIn noise consists of sea-state bias (SSB)- and SWH-related errors. The detailed error breakdown can be found in Esteban-Fernandez (2017). Here we use a simplified noise RMS as a function of the local SWH and the cross-track position (data provided by Dr. Esteban-Fernandez). The noise is the lowest in the middle of a swath and increases toward the edges (figure not shown). The dependence of the crosstrack location is eliminated by averaging the noise RMS in the cross-swath direction, resulting in a singlevariable function between noise RMS and SWH, which is then used to derive the noise spectrum level as follows. 


\section{d. Derivation of noise spectrum level from standard deviation}

It is important to note that the KaRIn noise is specified as the RMS of a Gaussian noise on a $1-\mathrm{km}^{2}$ pixel (Esteban-Fernandez 2017). It is therefore necessary to convert the RMS in centimeters to the power spectrum density in square centimeters per cycle per kilometer in order to evaluate the SNR in the wavenumber space.

The expected power spectrum density (PSD) of a white noise with variance $\sigma^{2}$ is constant for all wavenumbers $s_{0}^{2}=2 \Delta x_{0} \sigma_{0}^{2}$, where $s_{0}^{2}$ represent the PSD, $\Delta x_{0}$ is the grid spacing, and $\sigma_{0}^{2}$ is the associated noise variance for the grid. Note that averaging in $1 \mathrm{D}$ does not change this spectrum level for the following reason. An $N$-point averaging of a one-dimensional white noise reduces the noise variance to $\sigma_{1}^{2}=\sigma_{0}^{2} / N$, which is compensated by the increase of the sampling interval so that the noise spectrum remains invariant: $s_{1}^{2}=2 \Delta x_{1} \sigma_{1}^{2}=2 N \Delta x_{0}\left(\sigma_{0}^{2} / N\right)=s_{0}^{2}$, where $\Delta x_{1}, \sigma_{1}^{2}$, and $s_{1}^{2}$ represent the new pixel size, the noise variance, and the spectrum level, respectively. However, the noise spectrum floor can be reduced by $2 \mathrm{D}$ averaging of a $2 \mathrm{D}$ field. This advantage of SWOT over conventional nadir altimetry is documented in Esteban-Fernandez (2017) and included below.

\section{e. Additional noise reduction by averaging in two dimensions}

The variance of a white noise can be reduced by averaging. Given a white noise with variance $\sigma^{2}$, the new variance becomes $\sigma^{2} / N$ after $N$-point averaging. In this respect, the advantage of a $2 \mathrm{D}$ swath for noise reduction is that there are more pixels to average. Therefore, the noise variance will be reduced by a factor of $N^{2}$ instead of $N$, hence introducing extra noise reduction. ${ }^{1}$ The along-track one-dimensional wavenumber PSD of the KaRIn noise for a postprocessed coarser grid with a pixel size $\Delta x_{2} \times \Delta x_{2}$ is written as

$$
s_{2}^{2}=2 \Delta x_{2} \sigma_{2}^{2},
$$

where $\Delta x_{2}$ is the size of the coarse grid, chosen to be $7.5 \mathrm{~km}$ in this study, corresponding to the projected Nyquist wavelength of $15 \mathrm{~km}$; and $\sigma_{2}^{2}$ is the noise variance at the new coarse grid. We have $\sigma_{2}^{2}=\sigma_{0}^{2} / N^{2}$, where $N=\Delta x_{2} / \Delta x_{0}$. After substituting this relation into Eq. (1), the noise spectrum floor for the new grid becomes

\footnotetext{
${ }^{1}$ Note that the additional error reduction will be evident in the spectrum of the cross-swath averaged SSH in the original alongtrack resolution. The along-track averaging is not essential but included in the formulation for the consistency with the mission science requirement.
}

$$
s_{2}^{2}=\frac{2 \Delta x_{0}^{2} \sigma_{0}^{2}}{\Delta x_{2}} .
$$

Specifically, the noise PSD becomes $s_{2}^{2}=2 \sigma_{0}^{2} / 7.5$ after substituting $\Delta x_{2}=7.5 \mathrm{~km}$ and $\Delta x_{0}=1 \mathrm{~km}$, where again the noise RMS $\sigma_{0}$ of KaRIN was expressed for a pixel size $\Delta x_{0}=1 \mathrm{~km}$. For $\mathrm{SWH}=2 \mathrm{~m}, \sigma_{0}=2.5 \mathrm{~cm}$ as estimated from the SSH measurement performance (Esteban-Fernandez 2017), then $s_{2}^{2}=1.67 \mathrm{~cm}^{2}(\mathrm{cpkm})^{-1}$. This value is less than the measurement requirement of $2 \mathrm{~cm}^{2}(\mathrm{cpkm})^{-1}$, leaving a margin to meet the science requirement. The estimated performance corresponds to $2 \mathrm{~cm}^{2}(\mathrm{cpkm})^{-1}$ for SWH $=3 \mathrm{~m}$ (Fig. 1).

The $s_{2}$ derived from the cross-swath-averaged $\sigma_{0}$ is shown in Fig. 1, and $s_{2}$ is a function of SWH as a result of SWH dependence on $\sigma_{0}^{2}$. It is important to note that $s_{2}^{2}=2 \sigma_{0}^{2} / 7.5$ used in this study represents the noise floor of the estimated measurement performance for $7.5 \mathrm{~km} \times 7.5 \mathrm{~km}$ pixels.

\section{f. SWH-derived global KaRIn noise}

The altimetry SWH product from Queffeulou (2004) is used here to derive the realistic level of KaRIn noise. The SWH product of Queffeulou (2004) merges nine altimetry missions and buoy measurements after a consistent cross-mission calibration and validation. Data are available between 1992 and 2017, but we used only the 2016 data. As well documented (e.g., Young 1994), SWH has strong latitudinal dependence and seasonality, being small in low latitudes and during the summer season and large in high latitudes and during the winter season. This global and seasonal variation is mostly associated with the amplitude of the local wind (Young 1994).

The dependence of the KaRIn noise on SWH is not linear but nevertheless monotonic (Fig. 1). As a result, the KaRIn noise spectrum has a spatial and temporal distribution similar to SWH climatology (Fig. 2). The annual mean KaRIn noise spectrum is approximately $2 \mathrm{~cm}^{2}(\mathrm{cpkm})^{-1}$ in the midlatitudes and can be as high as $4 \mathrm{~cm}^{2}(\mathrm{cpkm})^{-1}$ in the Southern Ocean, which is significantly smaller than the $O\left(10^{2}\right) \mathrm{cm}^{2}(\mathrm{cpkm})^{-1}$ in the conventional altimeter (Dufau et al. 2016; Morrow et al. 2017). Strong seasonal variability indicated by seasonal difference (Fig. 2, bottom right) occurs in the Southern Ocean, the North Pacific, and the North Atlantic following the seasonality of SWH. A strong seasonality in the SWOT scale is consequently expected in these regions.

\section{g. Definition of the SWOT scale}

The SWOT scale $L_{s}$ is defined here as the wavelength where the SNR between the ocean signal and the SWOT error is equal to one. This definition is chosen 


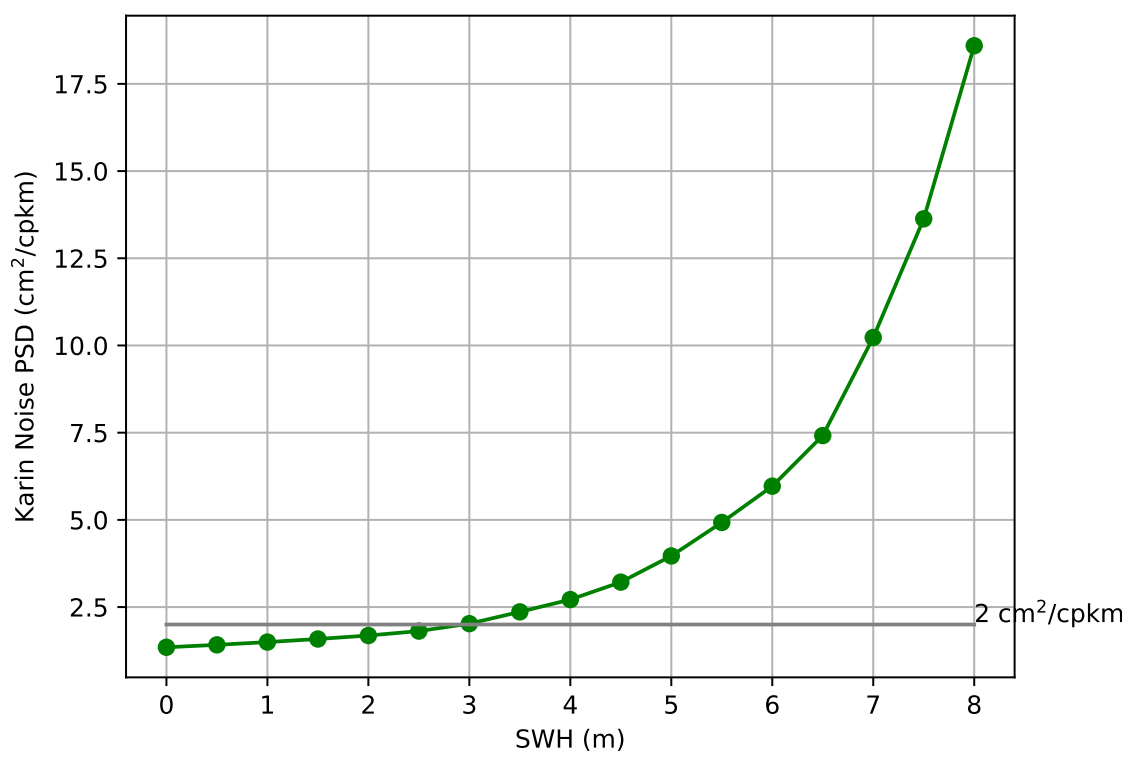

FIG. 1. Relationship between SWH and power spectra density of the associated KaRIn noise given in the instrument performance document (Esteban-Fernandez 2017) based on $7.5 \mathrm{~km} \times 7.5 \mathrm{~km}$ pixels. This pixel size is chosen to yield the $1 / 15 \mathrm{cpkm}$ Nyquist wavenumber in the science requirement document. The KaRIn noise is derived from the cross-swath-averaged RMS noise.

to be consistent with the mission science requirement (Rodriguez 2016) and the previous relevant study by FU14. The ocean signal is from the simulated SWOT SSH based on the LLC4320 simulation. The SWOT error $\left[\mathrm{cm}^{2}(\mathrm{cpkm})^{-1}\right]$ is represented by an analytic function- that

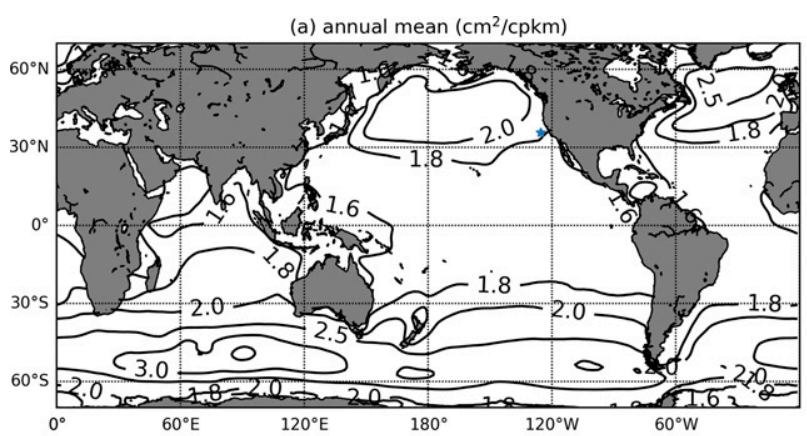

(c) FMA $\left(\mathrm{cm}^{2} / \mathrm{cpkm}\right)$

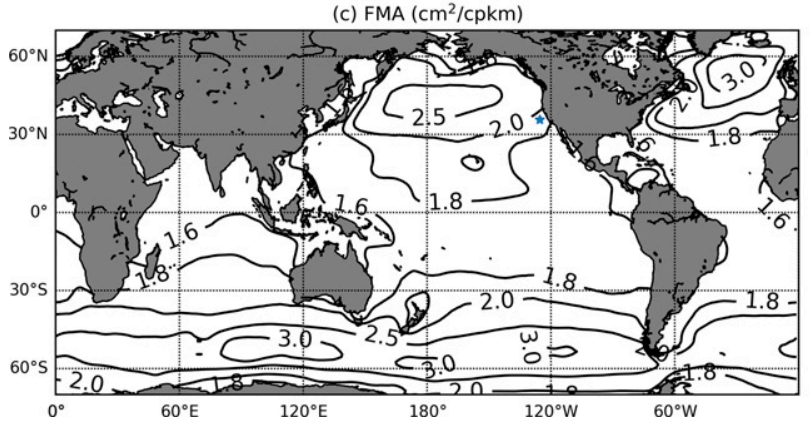

is, $E(k)=s_{2}^{2}+0.00125 k^{-2}$, where $k$ represent the alongtrack wavenumber and $s_{2}^{2}$ is the KaRIn white noise spectrum-and the wavenumber dependence represents these geophysical errors that dominate over large scales (Esteban-Fernandez 2017).

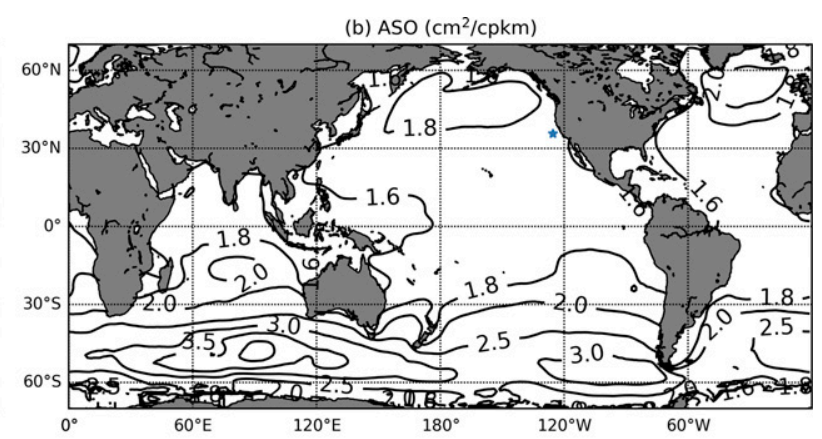

(d) ASO-FMA $\left(\mathrm{cm}^{2} / \mathrm{cpkm}\right)$

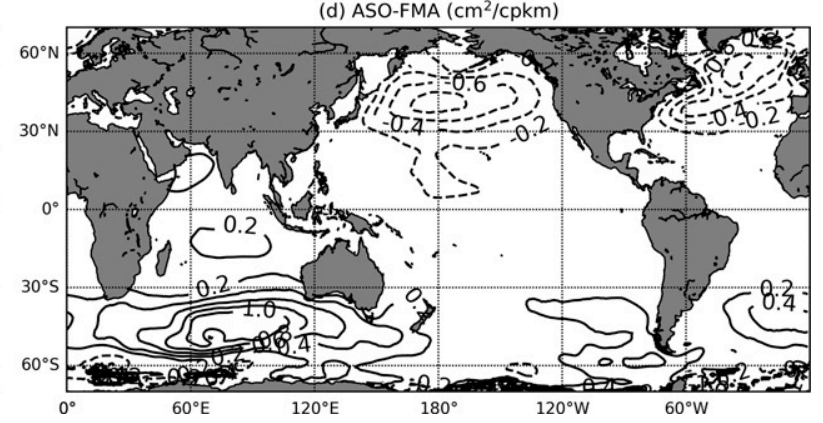

FIG. 2. KaRIn noise spectrum floor derived from SWH climatology. (a) The annual mean, (b) the ASO mean, (c) the FMA mean, and (d) the seasonal change (ASO minus FMA) are shown. 


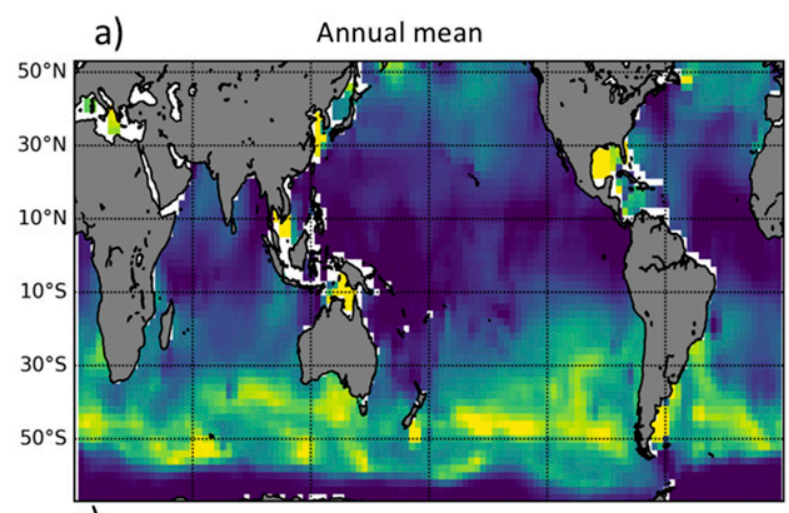

b)

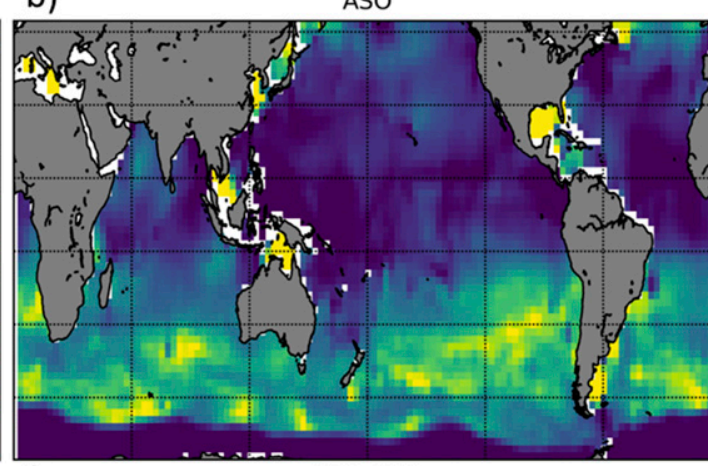

d)
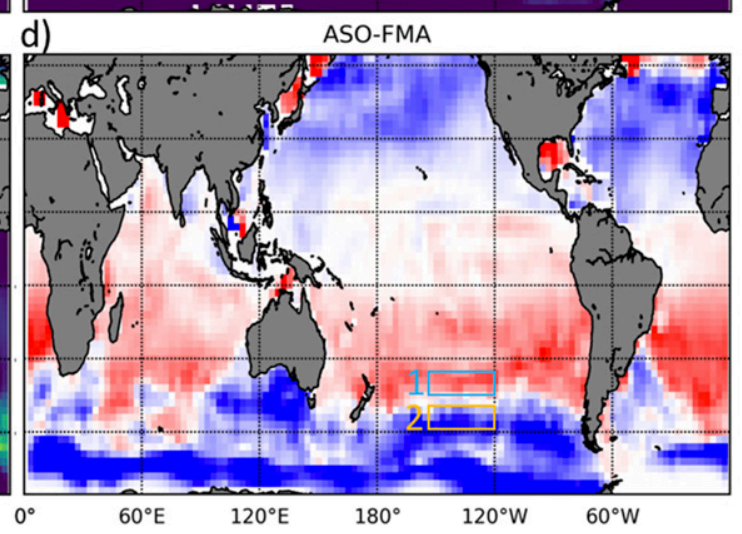
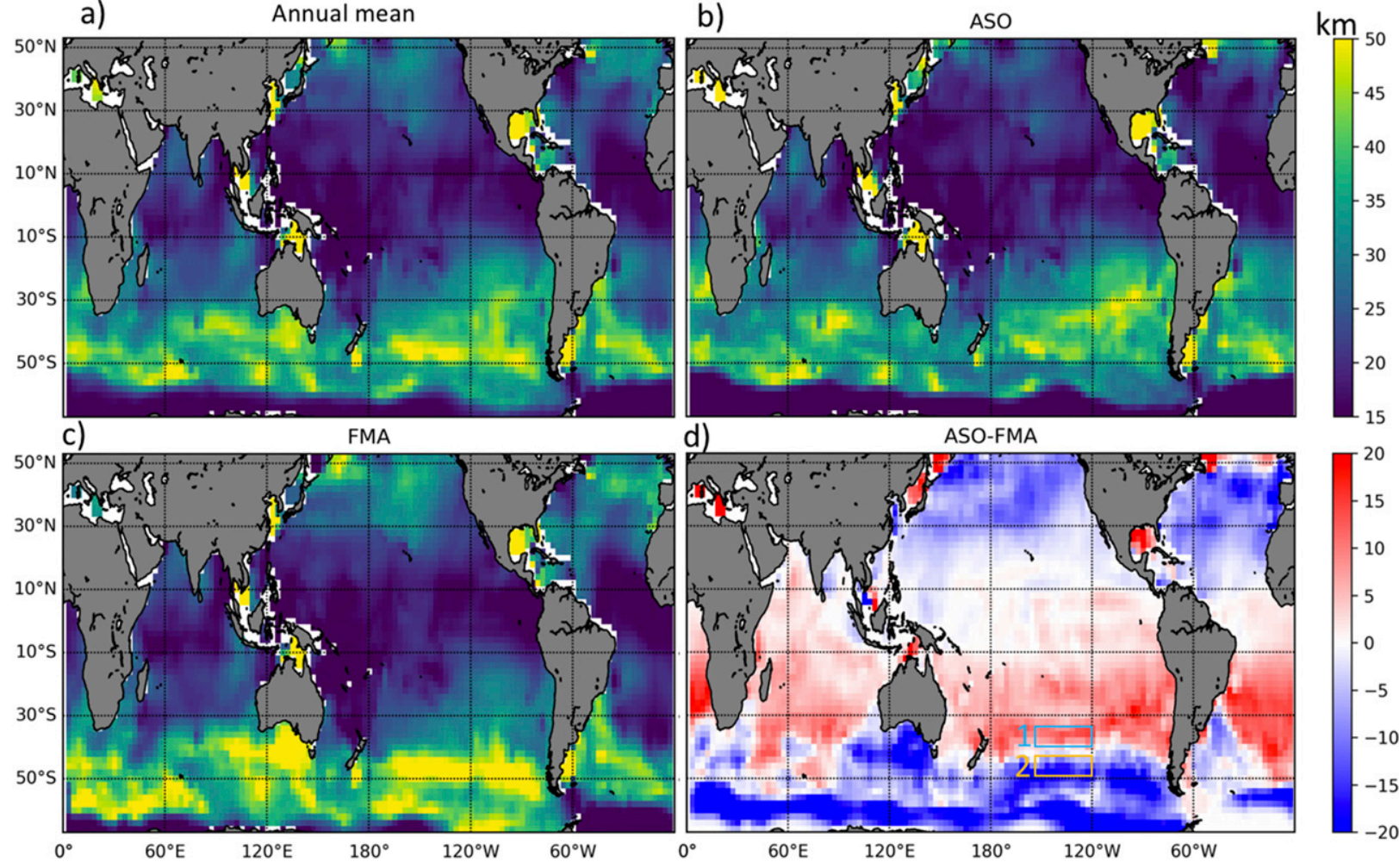

FIG. 3. SWOT scale averaged (a) annually, (b) in ASO, and (c) in FMA. (d) The seasonal change (ASO minus FMA) is shown. The domain-averaged wavenumber spectra for the two marked rectangular boxes in (d) are shown in Fig. 6.

In this study the wavenumber spectrum of the signal is calculated based on 600-km-long segments of the simulated SWOT swath. The diagnosed SWOT scale is assigned to the center of each segment. A Hanning window is applied to each linearly detrended segment for the wavenumber spectrum calculation, and the spectral variance is corrected accordingly to account for using this window tapering. The final cross-swath-averaged wavenumber spectrum is compared to the analytical function representing the error spectrum. Since the SWOT swath does not follow regular latitude-longitude grids, the scattered values of $L_{s}$ are binned and averaged onto $2^{\circ}$ latitude $\times 3^{\circ}$ longitude cells. There are 365 daily snapshots of $L_{s}$, representing a full annual cycle. The averages during February-April (FMA) and during August-October (ASO) represent the boreal winter and summer, respectively. Although this seasonal partition may not rigorously reflect the seasonality for some regions, given that different locations may have different seasonal peaks, it is nevertheless a useful indication of global seasonal variations. The global analyses of $L_{s}$ are shown in Fig. 3 and discussed in section $3 \mathrm{a}$.

Note that the SSH field used here is the total SSH, including the barotropic waves, atmospheric loading, and bottom pressure signals. We use total SSH instead of the dynamic topography because of computational difficulty in calculating dynamic height from the model's temperature and salinity output, which amounted to $\sim 2 \mathrm{~PB}$. However, it is shown that the large-scale atmospheric loading and bottom pressure signals can be eliminated by removing a 1D linear trend along a segment of several hundred kilometers (Wang et al. 2018). The along-track linear trend is removed from each $600-\mathrm{km}$-long segment of the simulated swath in our spectral analyses. In this respect, the results of the total $\mathrm{SSH}$ are equivalent to those of the ocean dynamic topography, except for coastal regions, where a simple spatial detrending operation may not be enough to remove external signals.

\section{Results}

\section{a. The global distribution}

The SWOT scale, as defined by the SNR, is naturally a result of the balance between the strength of the SSH signal and the amplitude of the SWOT error, which is mostly random noise at the high-wavenumber end. As shown in Fig. 3, the overall geographic distribution of the SWOT scale has the imprint of the SWH-induced 


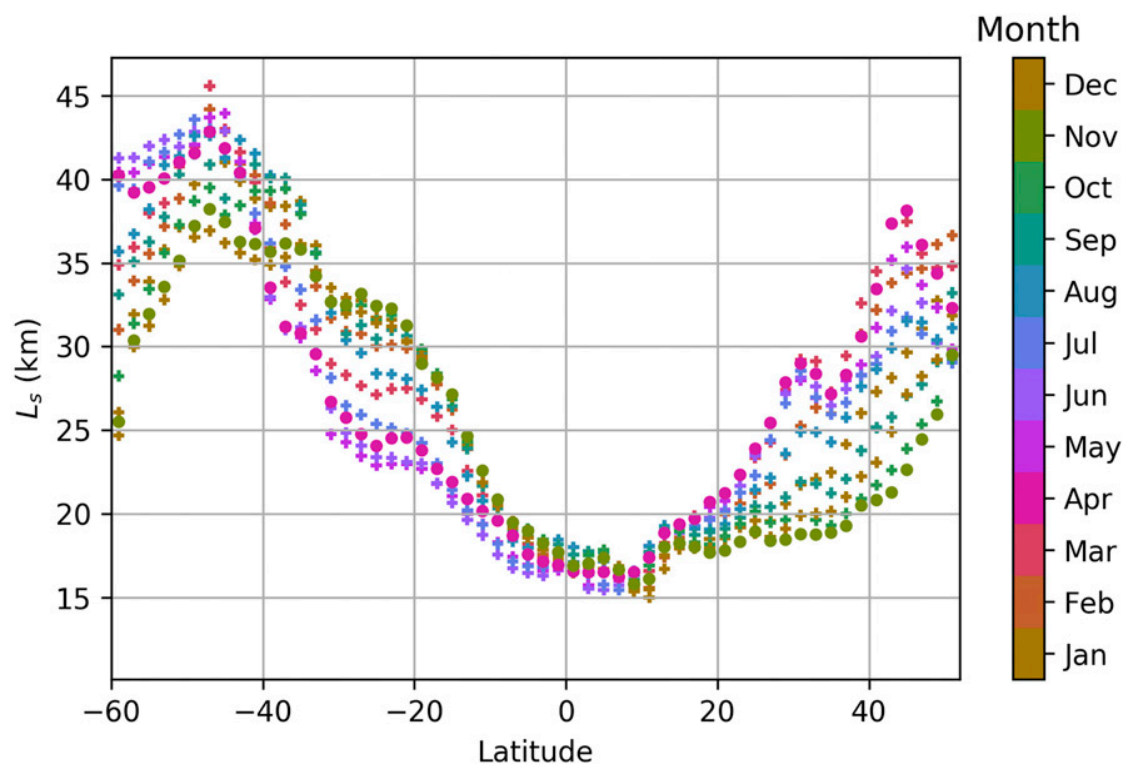

FIG. 4. Longitudinal median $L_{s}$ as a function of latitude ( $x$ axis) and month of year (color). Each symbol represents the median of $L_{s}$ within a $2^{\circ}$ latitudinal band for a particular month. The months of April and November are marked by the colored dots.

KaRIn noise, that is, smaller at the low latitudes, where the SWH is small, and larger at the high latitudes, especially in the Southern Ocean, where the SWH is large (Fig. 3). The SWOT scale increases from $\sim 15 \mathrm{~km}$ or less at the low latitudes to about 40 and $35 \mathrm{~km}$ in the high latitudes of the Southern and Northern Hemispheres, respectively (Fig. 4). The SWOT scale has a large spatial variation in the Southern Ocean and can be $\sim 60$ or $\sim 20 \mathrm{~km}$ depending on specific locations.

The large spatial variation in $L_{s}$ highlights the effect of the strength of the ocean signal. For example, the eddy energy is highly heterogeneous in the Southern Ocean as a result of the topographic modulation of the Antarctic Circumpolar Current (ACC) and its eddy field (Thompson and Sallée 2012). Over the quiet regions commonly found upstream of a major topographic feature such as the Kerguelen Plateau $\left(52^{\circ} \mathrm{S}, 60^{\circ} \mathrm{E}\right)$, the signal in the smaller mesoscale $(<50 \mathrm{~km})$ is weaker than the SWOT KaRIn noise level, leading to a unit SNR at a larger wavelength (larger $L_{s}$ ) (Fig. 3a). On the contrary, downstream of the Kerguelen Plateau $\left(52^{\circ} \mathrm{S}, 85^{\circ} \mathrm{E}\right)$, where energetic meso- and submesoscale eddies are spawned (Rosso et al. 2015), the SWOT scale is much smaller as a result of the stronger ocean signal even though the local SWH is among the highest in the global ocean. A closer examinations of the Kerguelen Plateau and several other regions can be found in section $3 \mathrm{c}$.

Our results are in good agreement with the previous study by Dufau et al. (2016) shown in Fig. 5. Dufau et al. (2016) briefly analyzed the SWOT scale using the
KaRIn noise level derived from the SWH averaged during the March-October period of 2013 and the noiseremoved spectrum from the Jason-2 altimeter. Their analyses are consistent with this study, presenting smaller $L_{s}$ in the equatorial regions and the energetic regions such as the Southern Ocean ACC and the western boundary Kuroshio and Gulf Stream extensions. The smaller $L_{s}$ in equatorial regions is due to the flatter wavenumber spectrum there. Smaller $L_{s}$ in the ACC and the western boundary currents is due to the large mesoscale eddy energy. Discrepancies exist over the east boundary of the oceanic gyres, such as the eastern North and South Pacific. The discrepancies are due to the local energetic IGWs, whose influences are included in this study but absent in the extrapolation of the wavenumber spectrum of the altimeter data from mesoscale (FU14; Dufau et al. 2016).

In summary, the spatial scales resolved by SWOT increase from $\leq 15 \mathrm{~km}$ in low latitudes to $\sim 30-45 \mathrm{~km}$ in high latitudes with a large geographic variation. Considering that the deformation radius, an indicator of the size of the energetic oceanic eddies, decreases toward higher latitudes, this opposite latitudinal dependence of the SWOT scale is an unfortunate reality, mostly because of a higher sea-state-induced instrument noise level at high latitudes. This elevated noise level also affects the conventional nadir-looking altimeters. However, the large regional dependence is worth emphasizing. The SWOT scale is smaller in the more energetic and dynamically important regions even in 


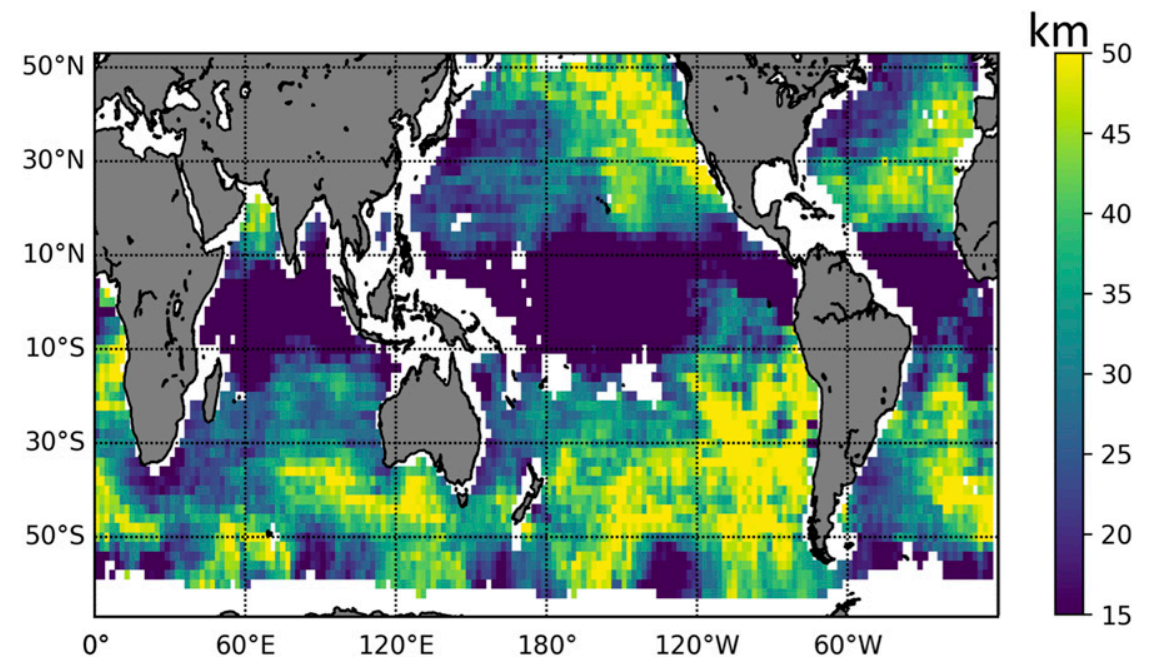

FIG. 5. Figure 10 of Dufau et al. (2016) regenerated using the same color scale as in Fig. 3 of this paper.

the high-latitude ACC and especially near the Drake Passage (discussed in section 3c; Fig. 8). It is one of the objectives of this study to extend the globally averaged SWOT scale $(15 \mathrm{~km})$ to a geographically and seasonally dependent quantity.

\section{b. The seasonal variability}

Seasonal variations in $L_{s}$ are expected and are clearly shown (Fig. 3d) as a result of the seasonal variations in both the SWH amplitude and the eddy energy. While it is physically easy to understand the geographical distribution of the seasonality in the noise (Fig. 2) and the ocean signal (Qiu et al. 2018), the seasonality of $L_{s}$ is rather complex as a result of the interplay between noise and signal. In addition, the SSH signal over the $15-150-\mathrm{km}$ wavelength band consists of two components, including the balanced eddy motions and the noticeably higher-frequency internal gravity waves (Müller et al. 2015), which exhibit an out-of-phase behavior in their seasonal variation, canceling each other to reduce the seasonality of the total SSH (Rocha et al. 2016b; Qiu et al. 2018). On a global scale, the seasonality map of the SWOT scale resembles the seasonality of the SWH; that is, KaRIn noise is smaller during local summer, so $L_{s}$ is smaller in summer given a similar oceanic signal. Noise-modulated seasonality occurs broadly over the North Pacific and Atlantic Oceans as well as the Southern Ocean. However, when the amplitude of the seasonal variation in the oceanic signal exceeds that of the local noise, the opposite phase of seasonality occurs, for example, several regions in the Southern Ocean within the ACC, mostly at latitudes higher than about $40^{\circ}$ (Fig. 3d).
The reversed seasonality in the Southern Ocean is due to the dominance of the seasonality of the ocean signal over that of noise. Figure 6 shows the wavenumber spectrum averaged in the two regions marked in Fig. 3d. The noise is higher during local winter (ASO; dashed lines) than during local summer (FMA; solid lines). However, the ocean signal has a much stronger seasonality, which compensates the seasonality of the noise and generates a reversed seasonality between these two locations on the two sides of $40^{\circ} \mathrm{S}$. Region 1 is in the subtropical gyre of the South Pacific north of the ACC (Fig. 3d). The SSH energy for scales smaller than $\sim 50 \mathrm{~km}$ is higher during FMA (as a result of enhanced IGWs) than during ASO, giving a larger $L_{s}$ during ASO and an $L_{s}$ seasonality consistent with the noise-dominated seasonality (Fig. 6, left panel). Region 2 is within the ACC. The SSH energy is much higher during Southern Hemisphere winter (ASO), yielding a reversed seasonality in $L_{s}$ (Fig. 6, right panel). The values of $L_{s}$ in these two regions are consistent with those shown in Fig. 3. More regional examples are discussed in section $3 \mathrm{c}$.

The pattern of $L_{s}$ shows small seasonal variations $(\sim 5 \mathrm{~km})$ at low latitudes and large variations $(\sim 10 \mathrm{~km})$ at high latitudes (Fig. 4). The low $L_{s}$ variation at the low latitudes is partially a resolution artifact caused by the saturated $L_{s}$ toward the $15-\mathrm{km}$ limit imposed by the 7.5-km grid.

As an example of the seasonal variation, the averaged $L_{s}$ within the $30^{\circ}-40^{\circ}$ band of both hemispheres is shown in Fig. 7. There is a clear phase reversal between the two hemispheres. The highest and lowest $L_{s}$ occur during March (October) and November (May), 


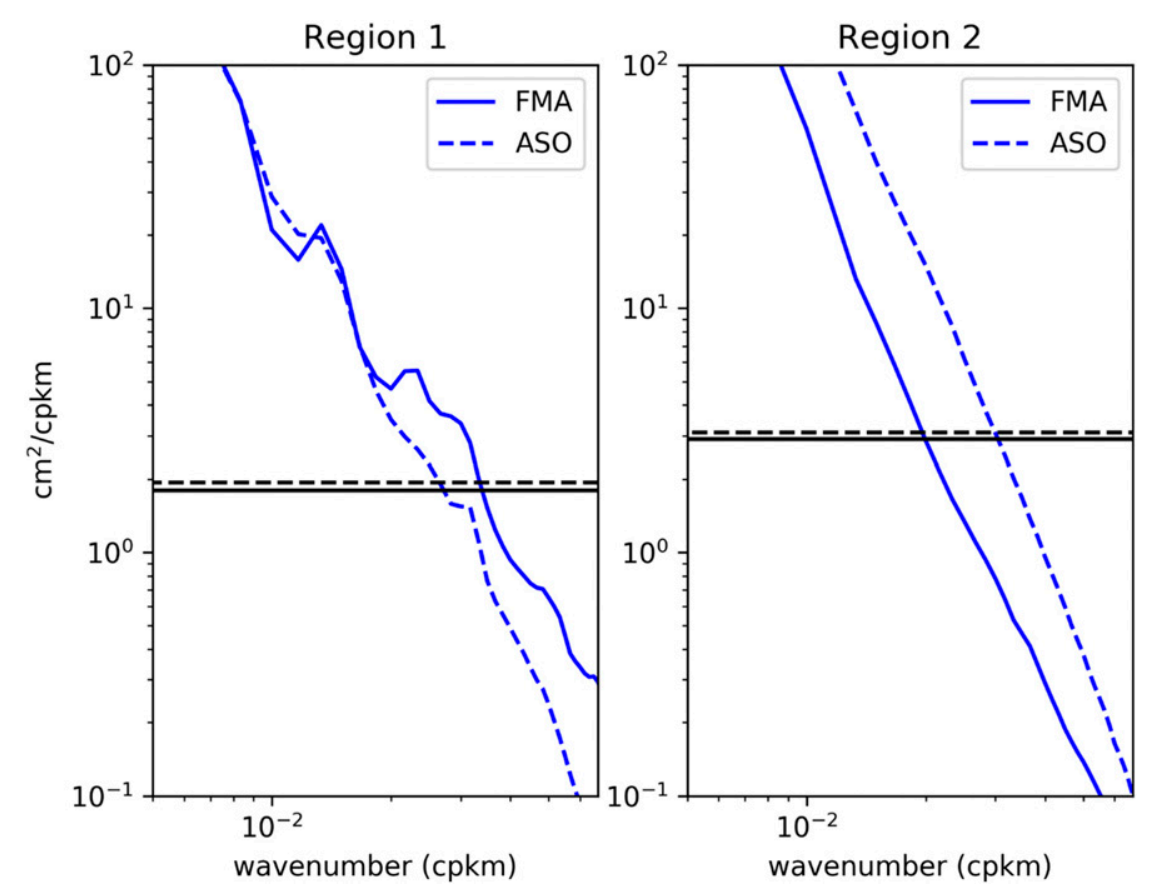

FIG. 6. SSH wavenumber spectra at the two locations marked by the numbers in Fig. $3 \mathrm{~d}$ for two seasons (ASO and FMA). Spectrum for (left) region 1 and (right) region 2. The dashed (solid) blue lines represent ASO (FMA) ocean signals. The black lines represent the noise levels. The blue lines are ocean signals.

respectively, for the Northern (Southern) Hemisphere. Because of different peaking times, no single period clearly exists for defining the $L_{S}$ seasonality globally. The Southern Ocean midlatitude has noticeably larger $L_{S}$ than the Northern Hemisphere, which is also evident in Fig. 3. We now focus on some regional examples that illustrate the local seasonality of $L_{S}$.

\section{c. Regional examples}

In addition to the global analyses, nine regional examples are shown in Fig. 8, in order to illustrate the

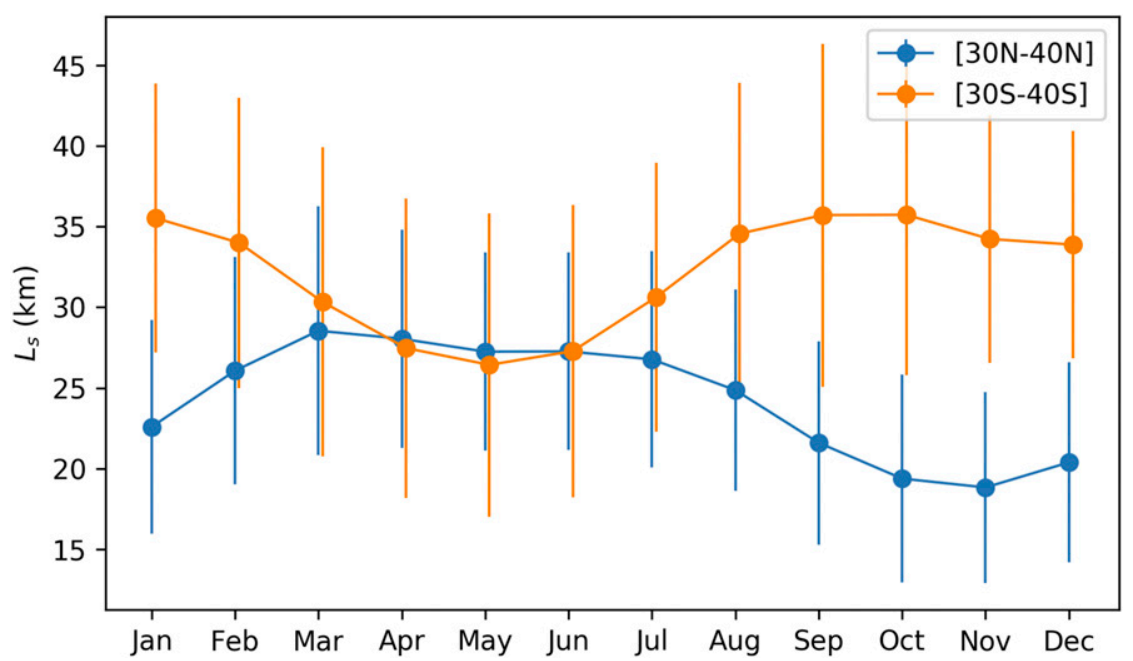

FIG. 7. The seasonal variations of the midlatitude SWOT scale $L_{s}$. The dots represent the mean of $L_{s}$ averaged within two latitude bands: $30^{\circ}-40^{\circ} \mathrm{S}$ (orange) and $30^{\circ}-40^{\circ} \mathrm{N}$ (blue). The error bars represent the standard deviation of $L_{s}$ within each latitudinal band for a particular month. 

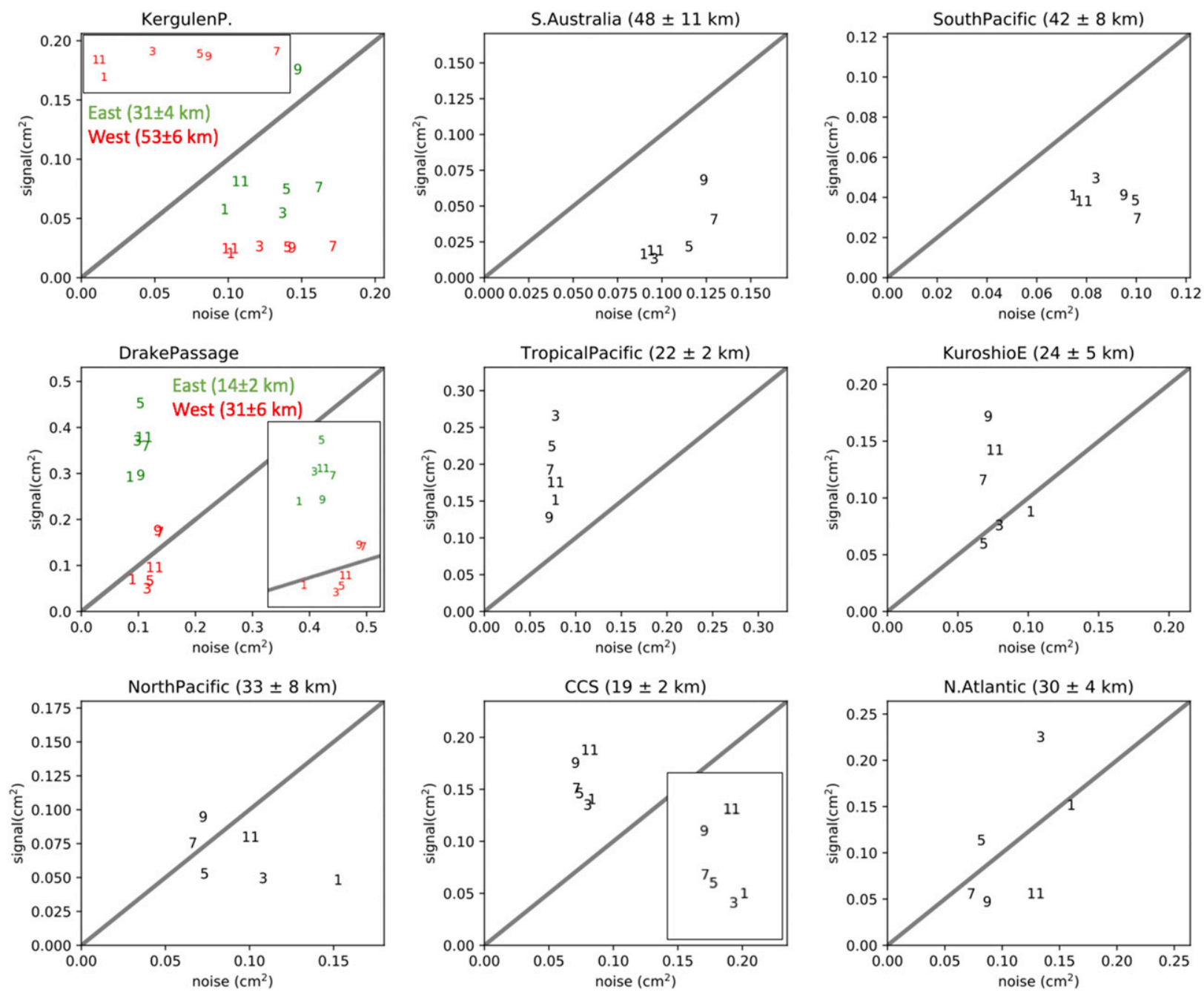

FIG. 8. SSH variance ( $y$ axis) and noise variance ( $x$ axis) as a function of month (numbers) for nine regions. The variance is derived from the integration between 15- and 30-km wavelengths to represent the small mesoscale range and averaged within a $2^{\circ} \times 3^{\circ}$ box. Their coordinates are listed in Table 1. The 1:1 ratio is indicated by the gray line, below which noise dominates and above which the signal dominates.

characteristics of different dynamical regimes. Their coordinates are listed in Table 1.

Each panel in Fig. 8 represents one region, as identified in the title. The Kerguelen Plateau and Drake Passage regions are further divided into up- and downstream to illustrate the sharp dynamical change within a short distance. The $x$ axis and $y$ axis represent the variances of the noise and the SSH signal, respectively, integrated between $15-$ and $30-\mathrm{km}$ wavelengths. The scattered numbers represent the month associated with the variances in the two axes. The signal exceeds noise for those numbers above the gray line (1:1 ratio), and vice versa.

The Kerguelen Plateau $\left(55^{\circ} \mathrm{S}, 55^{\circ}-90^{\circ} \mathrm{E}\right)$ region shows strong heterogeneity in local dynamics between west (upstream; red) and east (downstream; green) of the plateau, as mentioned in section 3a. The noise level and its variability are similar between west and east because the SWH has spatial scales much larger than the extent of the plateau. It is weakest from November through January and peaks in July. However, the ocean signal is much stronger to the east than to the west. As a result of the weaker upstream signal, $L_{s}$ is larger to the west of the plateau than to the east. No clear seasonal variation of the SSH signal appears to the west of the plateau but a large seasonality to the east, where the signal peaks in September when the SSH signal is stronger than the noise over the $15-30-\mathrm{km}$ range and hence is detectable. 
TABLE 1. The coordinates of the regions shown in Fig. 8.

\begin{tabular}{|c|c|c|c|c|c|}
\hline Region name & Coordinates & Region name & Coordinates & Region name & $\overline{\text { Coordinates }}$ \\
\hline East Kerguelen Plateau & $55^{\circ} \mathrm{S}, 90^{\circ} \mathrm{E}$ & West Kerguelen Plateau & $55^{\circ} \mathrm{S}, 55^{\circ} \mathrm{E}$ & Australia Bight & $43^{\circ} \mathrm{S}, 125^{\circ} \mathrm{E}$ \\
\hline South Pacific & $37^{\circ} \mathrm{S}, 110^{\circ} \mathrm{W}$ & East Drake Passage & $58^{\circ} \mathrm{S}, 60^{\circ} \mathrm{W}$ & Drake Passage West & $60^{\circ} \mathrm{S}, 80^{\circ} \mathrm{W}$ \\
\hline Tropical Pacific & $5^{\circ} \mathrm{N}, 150^{\circ} \mathrm{W}$ & Kuroshio Extension & $30^{\circ} \mathrm{N}, 150^{\circ} \mathrm{E}$ & North Pacific & $41^{\circ} \mathrm{N}, 18^{\circ} \mathrm{W}$ \\
\hline California Current System & $35^{\circ} \mathrm{N}, 125^{\circ} \mathrm{W}$ & North Atlantic & $56^{\circ} \mathrm{N}, 26^{\circ} \mathrm{W}$ & & \\
\hline
\end{tabular}

The Australian Bight $\left(43^{\circ} \mathrm{S}, 125^{\circ} \mathrm{E}\right)$ is a region associated with a weak SSH signal but a large noise. The seasonal variability is similar between the signal and the noise, which are both weak from November to March and strong from July to September. The weak signal below the noise level explains the large $L_{s}$ values in this region (Fig. 3).

The South Pacific $\left(37^{\circ} \mathrm{S}, 110^{\circ} \mathrm{W}\right)$ shows a weaker signal and a stronger noise with a larger seasonal variation in the noise than in the signal. The seasonality is weaker and slightly reverse compared to the Australian Bight, but the seasonal variability of the noise is similar between these two regions.

The Drake Passage $\left(58^{\circ} \mathrm{S}, 60^{\circ} \mathrm{W}\right)$ region shows a spatial heterogeneity between upstream (west) and downstream (east), which is similar to what is shown near the Kerguelen Plateau. The signal is stronger downstream than upstream. The noise is relatively weak compared to the strength of the local signal but nonetheless with a similar amplitude to other regions of the Southern Ocean. It is clear that the seasonality of $L_{s}$ near the Drake Passage is overall controlled by the signal.

The tropical Pacific $\left(5^{\circ} \mathrm{N}, 150^{\circ} \mathrm{W}\right)$ has a very low noise level but a strong signal. The signal has a strong seasonal variation in contrast to the weak seasonal variation in the noise level. The variance in the signal is always above the noise for these spatial scales $(15-30 \mathrm{~km})$, explaining the small $L_{s}$ at the low latitudes (Fig. 3).

The Kuroshio Extension $\left(30^{\circ} \mathrm{N}, 150^{\circ} \mathrm{E}\right)$ has similar signal and noise strength variations between signal and noise from January to May, but it is dominated by signal from June to December. Therefore, the seasonality is also dominated by the seasonality of the signal, which peaks in September when the unbalanced IGWs are energetic (Qiu et al. 2018).

The central North Pacific $\left(41^{\circ} \mathrm{N}, 18^{\circ} \mathrm{W}\right)$ has similar signal and noise amplitudes, but the noise controls the seasonal variation. The noise is highest during January (the boreal winter). The signal is also the weakest from January to May but peaks during September.

The California Current System $\left(35^{\circ} \mathrm{N}, 125^{\circ} \mathrm{W}\right)$ has a stronger noise dependence. The noise field shows little seasonality. The seasonal variation of $L_{s}$ is controlled by the strength of the signal, which peaks in late fall during (November) and is weakest during March.

The high-latitude North Atlantic $\left(56^{\circ} \mathrm{N}, 26^{\circ} \mathrm{W}\right)$ shows high amplitudes in both the SSH signal and the noise, both contributing to the observed seasonality in $L_{s}$. The noise level is highest in January and lowest in July, similar to the other regions in the Northern Hemisphere. The signal level is highest in March and lowest in September.

To summarize, the above regional examples highlight the diverse variability in the SNR and the associated $L_{s}$. While the noise level has a large-scale seasonal variation associated with atmospheric winds, the ocean signal and its seasonal variation have a strong local dependence. We need to treat each region differently when interpreting the future SWOT measurement.

\section{d. Can SWOT resolve the transition from eddy motion to waves?}

When the spatial scale decreases from several hundred kilometers down to tens of kilometers, the SSH variance shifts from (eddy) balanced-motion dominant to wave dominant (Qiu et al. 2018). Qiu et al. (2018) showed that the wavenumber spectra of the balanced and IGWs intersect at wavelengths from about 10 to $\sim 200 \mathrm{~km}$, depending on specific locations. This wavelength is referred to as the transition scale $L_{t}$ in Qiu et al. (2018) and marks the spatial scale below which the IGWs become prominent in the SSH signals, and the separation of waves and balanced motions becomes a challenge for satellite altimetry, whose temporal resolution is insufficient to resolve the frequency spectrum of high-frequency waves. Can SWOT resolve this transition scale, that is, measure the SSH signal of IGWs?

As we can anticipate from the variations of $L_{t}$, the answer to this question will have a regional dependence. Figure 9 shows the annual mean of the difference between $L_{t}$ and $L_{s}$. The negative values (blue shading) mean that the SWOT scale is larger than the transition scale, so SWOT will not observe IGWs, and vice versa. Most of the Southern Ocean ACC regions, a small area near the western boundary currents (Kuroshio and Gulf Stream) and the North Atlantic Ocean, show a negative 

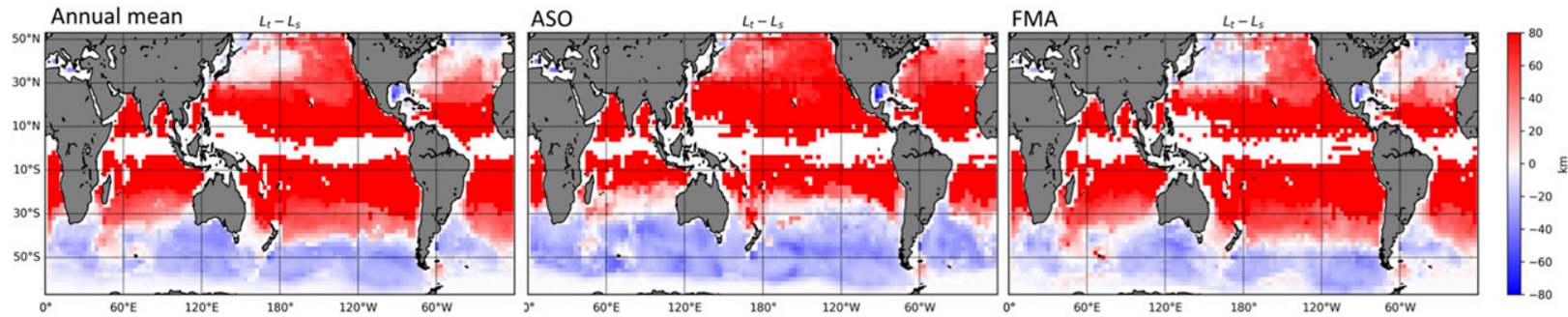

FIG. 9. The difference between the transition scale $L_{t}$ (Qiu et al. 2018) and the SWOT scale $L_{s}$. Negative values (blue shading) mean that $L_{s}$ is larger than $L_{t}$, so SWOT will not observe the transition between balanced and wave motions in spectra space, and vice versa for the positive values (red shading).

$L_{t}-L_{s}$. These negative values are partly because of the smaller $L_{t}$ as a result of the relatively weak IGWs and partly because of the large $L_{s}$ as a result of the high SWH-induced instrument noise. The IGWs will not be an issue for these regions within the SWOT measurements especially during summertime. However, for the rest of the ocean, SWOT can clearly see the transition scale. This indicates that the mission can provide valuable information for studying IGWs over these regions. It also highlights the fact that developing a method that distinguishes balanced motions from waves, which naturally leads to their separation, becomes one of the mission's top priorities in order to maximize the potential of the SWOT measurements.

\section{Concluding remarks}

The SWOT scale, defined as the wavelength where sea surface height signal-to-noise ratio becomes one, has been reexamined in this study. The ocean signal at small scales is derived from a high-resolution tide-resolving global ocean simulation. The SWOT error is a combination of a fixed correlated error and a random KaRIn noise estimated from an altimetry-derived significant wave height product. We used only 2016 data, as the SWH has a dominant seasonal cycle but little interannual variability. The results show that (i) the SWOT scale increases from $\leq 15 \mathrm{~km}$ at the low latitudes to $\sim 30-45 \mathrm{~km}$ at the high latitudes, with a strong longitudinal variation especially in the ACC; (ii) large seasonality exists as a result of the seasonal variation in both the ocean signal and the SWH-induced instrument noise; and (iii) the SWOT measurements will reveal an SSH field with a significant entanglement between ageostrophic internal gravity waves and geostrophically balanced motions over most of the world's oceans except for a large part of the Southern Ocean and the high-latitude North Atlantic and the Kuroshio Extension during winter.

Despite caveats regarding the realism of the simulation used in this study, our results highlight the spatial heterogeneity and the seasonality of the smallest-scale signals that will be resolved by SWOT. A more accurate determination of the SWOT scale and the associated spatial and temporal variations are important for the postlaunch processing of the SWOT data, in terms of more improved assimilation of SWOT measurements, by considering a time-space-varying SNR, and accurately interpreting the altimeter measurements for separating internal gravity waves versus balanced motions and the associated energetics.

Acknowledgments. We thank Bia Villas Boas, Joern Callies, Sarah Gille, Rosemary Marrow, and Clement Ubelmann for their helpful input. The comments from Cesar Rocha and an anonymous reviewer helped improve the readability of the paper. The research for this paper was carried out at the Jet Propulsion Laboratory, California Institute of Technology, under a contract with the National Aeronautics and Space Administration. The authors would like to acknowledge the funding sources for this study: the SWOT mission (JW, LF, DM); NASA Projects NNX16AH66G and NNX17AH33G (BQ, SC); and the NASA Physical Oceanography (PO) and Modeling, Analysis, and Prediction (MAP) Programs (HT, DM). We thank C. Dufau for sharing the data plotted in Fig. 4. High-end computing resources were provided by the NASA Advanced Supercomputing (NAS) Division at the Ames Research Center. The dataset used in this study is too large to share in a public domain but is available upon request.

\section{REFERENCES}

Arbic, B., and Coauthors, 2018: A primer on global internal tide and internal gravity wave continuum modeling in HYCOM and MITgcm. New Frontiers in Operational Oceanography, E. P. Chassignet et al., Eds., GODAE OceanView, 307-392, https://doi.org/10.17125/gov2018.ch13.

Bühler, O., J. Callies, and R. Ferrari, 2014: Wave vortex decomposition of one-dimensional ship-track data. J. Fluid Mech., 756, 1007-1026, https://doi.org/10.1017/jfm.2014.488.

Chelton, D., M. Schlax, and R. Samelson, 2011a: Global observations of nonlinear mesoscale eddies. Prog. Oceanogr., 91, 167216, https://doi.org/10.1016/j.pocean.2011.01.002. 
_ , P. Gaube, M. Schlax, J. Early, and R. Samelson, 2011b: The influence of nonlinear mesoscale eddies on near-surface oceanic chlorophyll. Science, 334, 328-332, https://doi.org/10.1126/ science.1208897.

Church, J. A., and N. J. White, 2006: A 20th century acceleration in global sea-level rise. Geophys. Res. Lett., 33, L01602, https:// doi.org/10.1029/2005GL024826.

Ducet, N., P. Y. Traon, and G. Reverdin, 2000: Global highresolution mapping of ocean circulation from TOPEX/Poseidon and ERS-1 and -2. J. Geophys. Res., 105, 19477-19498, https:// doi.org/10.1029/2000JC900063.

Dufau, C., M. Orsztynowicz, G. Dibarboure, R. Morrow, and P. Traon, 2016: Mesoscale resolution capability of altimetry: Present and future. J. Geophys. Res. Oceans, 121, 4910-4927, https://doi.org/10.1002/2015JC010904.

Durand, M., L.-L. Fu, D. P. Lettenmaier, D. E. Alsdorf, E. Rodriguez, and D. Esteban-Fernandez, 2010: The surface water and ocean topography mission: Observing terrestrial surface water and oceanic submesoscale eddies. Proc. IEEE, 98, 766-779, https://doi.org/10.1109/JPROC.2010.2043031.

Esteban-Fernandez, D., 2017: SWOT project: Mission performance and error budget. Revision A, Jet Propulsion Laboratory Doc. JPL D-79084, 117 pp.

Forget, G., J.-M. Campin, P. Heimbach, C. N. Hill, R. M. Ponte, and C. I. Wunsch, 2015: ECCO version 4: An integrated framework for non-linear inverse modeling and global ocean state estimation. Geosci. Model Dev., 8, 3071-3104, https:// doi.org/10.5194/gmd-8-3071-2015.

Fu, L.-L., and R. Ferrari, 2008: Observing oceanic submesoscale processes from space. Eos, Trans. Amer. Geophys. Union, 89, 488, https://doi.org/10.1029/2008EO480003.

— altimeter to swath altimeter for observing global ocean surface topography. J. Atmos. Oceanic Technol., 31, 560-568, https:// doi.org/10.1175/JTECH-D-13-00109.1.

— D. Chelton, P. Le Traon, and R. Morrow, 2010: Eddy dynamics from satellite altimetry. Oceanography, 23, 14-25, https://doi.org/10.5670/oceanog.2010.02.

Gaube, P., D. B. Chelton, P. G. Strutton, and M. J. Behrenfeld, 2013 Satellite observations of chlorophyll, phytoplankton biomass, and Ekman pumping in nonlinear mesoscale eddies. J. Geophys. Res. Oceans, 118, 6349-6370, https://doi.org/10.1002/2013JC009027.

Gaultier, L., C. Ubelmann, and L.-L. Fu, 2016: The challenge of using future SWOT data for oceanic field reconstruction. J. Atmos. Oceanic Technol., 33, 119-126, https://doi.org/ 10.1175/JTECH-D-15-0160.1.

IPCC, 2014: Climate Change 2014: Impacts, Adaptation, and Vulnerability. Part A: Global and Sectoral Aspects. Cambridge University Press, 1132 pp., https://doi.org/10.1017/CBO9781107415379.

Jayne, S., and J. Marotzke, 2002: The oceanic eddy heat transport. J. Phys. Oceanogr., 32, 3328-3345, https://doi.org/10.1175/ 1520-0485(2002)032<3328:TOEHT >2.0.CO;2.

Klein, P., and G. Lapeyre, 2009: The oceanic vertical pump induced by mesoscale and submesoscale turbulence. Annu. Rev. Mar. Sci., 1, 351-375, https://doi.org/10.1146/annurev. marine.010908.163704.

Large, W., and S. Yeager, 2004: Diurnal to decadal global forcing for ocean and sea-ice models: The data sets and flux climatologies. NCAR Tech. Note NCAR/TN-460+STR, 105 pp., https://doi.org/10.5065/D6KK98Q6.

Marshall, J., C. Hill, and L. Perelman, 1997: Hydrostatic, quasihydrostatic, and nonhydrostatic ocean modeling. J. Geophys. Res., 102, 5733-5752, https://doi.org/10.1029/96JC02776.
McWilliams, J., 2016: Submesoscale currents in the ocean. Proc. Roy. Soc. London, 472A, 20160117, https://doi.org/10.1098/ rspa.2016.0117.

Morrow, R., A. Carret, F. Birol, F. Nino, G. Valladeau, F. Boy, C. Bachelier, and B. Zakardjian, 2017: Observability of fine-scale ocean dynamics in the northwestern Mediterranean Sea. Ocean Sci., 13, 13-29, https://doi.org/10.5194/os-13-13-2017.

Müller, M., B. Arbic, J. Richman, J. Shriver, E. Kunze, R. Scott, A. Wallcraft, and L. Zamudio, 2015: Toward an internal gravity wave spectrum in global ocean models. Geophys. Res. Lett., 42, 3474-3481, https://doi.org/10.1002/2015GL063365.

Qiu, B., T. Nakano, S. Chen, and P. Klein, 2017: Submesoscale transition from geostrophic flows to internal waves in the northwestern Pacific upper ocean. Nat. Commun., 8, 14055, https://doi.org/10.1038/ncomms14055.

, S. Chen, P. Klein, J. Wang, H. Torres, L.-L. Fu, and D. Menemenlis, 2018: Seasonality in transition scale from balanced to unbalanced motions in the World Ocean. J. Phys. Oceanogr., 48, 591-605, https://doi.org/10.1175/JPO-D-17-0169.1.

Queffeulou, P., 2004: Long-term validation of wave height measurements from altimeters. Mar. Geod., 27, 495-510, https:// doi.org/10.1080/01490410490883478.

Rhines, P., 1971: A note on long-period motions at Site D. DeepSea Res. Oceanogr. Abstr., 18, 21-26, https://doi.org/10.1016/ 0011-7471(71)90012-X.

Rocha, C. B., T. K. Chereskin, S. T. Gille, and D. Menemenlis, 2016a: Mesoscale to submesoscale wavenumber spectra in Drake Passage. J. Phys. Oceanogr., 46, 601-620, https://doi.org/ 10.1175/JPO-D-15-0087.1.

, S. T. Gille, T. Chereskin, and D. Menemenlis, 2016b: Seasonality of submesoscale dynamics in the Kuroshio Extension. Geophys. Res. Lett., 43, 11304-11311, https://doi.org/10.1002/ 2016GL071349.

Rodriguez, E., 2016: Surface Water and Ocean Topography Mission (SWOT) project: Science requirements document. Jet Propulsion Laboratory Doc. JPL D-61923, 28 pp.

Rosso, I., A. M. Hogg, A. E. Kiss, and B. Gayen, 2015: Topographic influence on submesoscale dynamics in the Southern Ocean. Geophys. Res. Lett., 42, 1139-1147, https://doi.org/10.1002/ 2014GL062720.

Savage, A., and Coauthors, 2017: Spectral decomposition of internal gravity wave sea surface height in global models. J. Geophys. Res. Oceans, 122, 7803-7821, https://doi.org/10.1002/2017JC013009.

$\mathrm{Su}, \mathrm{Z}$., J. Wang, P. Klein, A. F. Thompson, and D. Menemenlis, 2018: Ocean submesoscales as a key component of the global heat budget. Nat. Commun., 9, 775, https://doi.org/10.1038/ s41467-018-02983-w.

Thompson, A. F., and J.-B. Sallée, 2012: Jets and topography: Jet transitions and the impact on transport in the Antarctic Circumpolar Current. J. Phys. Oceanogr., 42, 956-972, https:// doi.org/10.1175/JPO-D-11-0135.1.

Thompson, R., 1971: Topographic Rossby waves at a site north of the Gulf Stream. Deep-Sea Res. Oceanogr. Abstr., 18, 1-19, https://doi.org/10.1016/0011-7471(71)90011-8.

Wang, J., L.-L. Fu, B. Qiu, D. Menemenlis, J. T. Farrar, Y. Chao, A. F. Thompson, and M. M. Flexas, 2018: An observing system simulation experiment for the calibration and validation of the surface water ocean topography sea surface height measurement using in situ platforms. J. Atmos. Oceanic Technol., 35, 281-297, https://doi.org/10.1175/JTECH-D-17-0076.1.

Young, I. R., 1994: Global ocean wave statistics obtained from satellite observations. Appl. Ocean Res., 16, 235-248, https:// doi.org/10.1016/0141-1187(94)90023-X. 